\title{
A aprendizagem da leitura e da escrita entre negras e negros escravizados no Brasil: as várias histórias dos "sem arquivos"
}

\author{
Reading and writing learning among enslaved black people in Brazil: stories of the \\ "unrecorded"
}

El aprendizaje de la lectura y de la escritura entre negras y negros esclavizados en Brasil: las variadas historias de los "sin archivos"

\author{
Eliane Peres \\ Universidade Federal de Pelotas (Brasil) \\ Bolsista de Produtividade em Pesquisa do CNPq \\ https://orcid.org/0000-0002-0160-1276 \\ http://lattes.cnpq.br/5179048135412088 \\ eteperes@gmail.com
}

\section{RESUMO}

Neste artigo trabalha-se com anúncios de jornais das primeiras décadas do século XIX com o objetivo de identificar onde, como e com quem, homens, mulheres e crianças escravizadas aprendiam a ler e a escrever. A pesquisa indica que, via de regra, nas próprias residências, padres, senhoras, moças vindas da Europa, por exemplo, estavam entre as pessoas que ensinavam escravos e escravas as habilidades da leitura e da escrita. Além disso, um dos resultados do estudo revela a relação entre o ensino das primeiras letras e o ensino de tarefas domésticas e de ofícios especializados, como indicam os próprios anúncios analisados.

Palavras-chave: Escravos. Leitura. Escrita. 


\begin{abstract}
This paper analyzes newspapers ads from the first decades of the $19^{\text {th }}$ century to identify where, how, and from whom enslaved men, women, and children learned to read and to write. This research indicates that, in general, priests, ladies, young women from Europe, for example, were the people who taught reading and writing skills to enslaved people, in their own home. Furthermore, this study shows the relation between teaching those first letters and teaching skills used in home chores and in specialized labor, as the ads themselves reveal.
\end{abstract}

Keywords: Slaves. Reading.Writing

\title{
RESUMEN
}

En este artículo se trabaja con anuncios de periódicos de las primeras décadas del siglo XIX con el objetivo de identificar dónde, cómo y con quien, hombres, mujeres y niños esclavizados aprendían a leer y a escribir. La pesquisa indica que, como regla, en las propias residencias, curas, señoras y señoritas de Europa, por ejemplo, estaban entre las personas que enseñaban esclavos y esclavas las habilidades de la lectura y de la escritura. Además de eso, uno de los resultados del estudio revela la relación entre la enseñanza de las primeras letras, de las tareas domésticas y de oficios especializados, como indican los propios anuncios analizados.

Palabras clave: Esclavos. Lectura. Escritura. 


\section{Introdução}

A História enfrenta sempre esse grande óbice, que cabe aos investigadores ultrapassar: o silêncio sobre o que muito se calou ou escondeu. O que não honra. O lixo faz-se desaparecer, os cadáveres emparedamse e tudo deixa de existir. Não vimos, não sabemos, nunca ouvimos falar, não demos por nada. (FIGUEIREDO, 2015, p. 8).

Depois de um longo período de silêncio, a educação e a instrução da população escravizada no Brasil têm sido tema de importantes estudos, sendo crescente no país o interesse por tal temática em diferentes áreas de conhecimento ${ }^{1}$. Mesmo assim, pode-se dizer que tais estudos são, ainda, insuficientes. Muito há para ser feito no que se refere à identificação e a compreensão de processos educativos e escolares de escravos e escravas no Brasil.

Este artigo tem como objetivo principal contribuir com essa temática de investigação. Ele tem, contudo, um propósito mais específico: procura identificar processos de ensino e de aprendizagem inicial da leitura e da escrita entre a população escravizada (onde, como e com quem, homens, mulheres e crianças escravizadas aprendiam a ler e a escrever). Para isso, parte-se de algumas questões basilares, entre elas a mais simples e aparentemente óbvia: negras e negros escravizados aprendiam a ler e a escrever? Um conjunto de estudos já realizados, acerca do domínio da leitura e da escrita entre essa população, indica que sim, mesmo que esse número possa não ter sido assim tão expressivo.

Segundo Fonseca (2002, p. 11), em 1835 "foi legalmente determinado que os escravos não poderiam freqüentar escolas e que estas seriam franqueadas somente aos homens livres". Mas, ainda segundo o autor, no final dos anos de 1860, "a escolarização - ou algo muito próximo disso - passou a ser apresentada como uma dimensão fundamental para a vida dos escravos e libertos" (FONSECA, 2002, p. 11). Em razão da observação do autor e da indicação dos poucos estudos para as primeiras décadas do século XIX, o objetivo principal do estudo aqui apresentado é analisar dados referentes ao período anterior a 1835.

Assim, na sequência da pergunta básica que alavancou esse estudo, questionou-se: como escravos e escravas aprendiam a ler e a escrever? Onde aprendiam e quem os ensinava? Quais materiais eram usados para ensinar a leitura e a escrita para essa população? Esses questionamentos, na sua totalidade, não serão respondidos no presente artigo. Contudo, ressalta-se que eles são basilares e motivadores da pesquisa e conduziram a coleta de dados.

É preciso salientar, inicialmente, que a história do ensino da leitura e da escrita no Brasil é fundamentalmente aquela dos sujeitos e grupos sociais que têm visibilidade, ou seja, das populações com prestígio e posição socioeconômica e cultural favoráveis. Em outros contextos, contudo, a pesquisa dessa temática tem sido relativamente diferente:

A Europa e os Estados Unidos conjugam esse lugar com um outro, em que estão dando vez aos que se pensavam 'carecidos de letras'. Por exemplo: na Itália, estuda-se a escrita das gentes comuns de todas as épocas; em Portugal, os escritos dos presos da inquisição, também pessoas sem representatividade social, ganharam um livro só para eles; na Espanha, loucos, escravos, mulheres, presos etc e a sua manifestação por escrito mereceram uma coletânea de artigos. No Brasil, em épocas passadas, os 'carecidos de tudo' vem se

\footnotetext{
${ }^{1}$ Entre outros ver, Moysés (1994); Oro (2002); Wissenbach (2002); Oliveira (2005); Morais (2007); Barbosa (2009); Luz (2013); Bastos (2016).
} 
sobressaindo na História com os seus múltiplos temas: revoltas de escravos, o mundo dos libertos, mendigos, moleques e vadios, vida familiar e afetiva de escravos etc. Quanto à leitura e à escrita, raríssimos são os trabalhos que trilham esse caminho; os poucos de que se têm notícias conjugam o tema com os negros. (OLIVEIRA, 2005, p. 2. Grifo meu).

Nesse sentido, este trabalho pretende ser uma contribuição aos estudos sobre práticas de instrução em geral e sobre as aprendizagens e usos da leitura e da escrita em específico, de populações historicamente excluídas e marginalizadas no Brasil, ainda na conjugação indicada pelo autor supracitado. No caso específico, então, trata-se de um esforço de identificar onde, como, com quem, homens, mulheres e crianças escravizadas aprendiam a ler e a escrever. Há indicadores de que eles aprendiam em espaços domésticos e religiosos, por exemplo, com padres, com preceptoras dos filhos de seus algozes (acompanhando e ouvindo as lições), com benfeitores, etc. Os dados coletados na pesquisa que originou este artigo - todos localizados em jornais que circularam em diferentes estados do Brasil e que estão disponíveis na Hemeroteca Digital da Biblioteca Nacional ${ }^{2}$ - permitem algumas problematizações nesse sentido. Enfatizase que aqui foram destacados anúncios de jornais do Rio de Janeiro e exclusivamente das três primeiras décadas do século XIX ${ }^{3}$, isso porque "percebe-se que é pequena, na historiografia brasileira, a produção sobre a relação de escravos e ex-escravos com o mundo letrado, ressaltando-se o fato de que, até o presente momento, poucos debruçam sobre o século XVIII e a primeira metade do XIX" (MORAIS, 2007, p. 497).

$\mathrm{Na}$ perspectiva das "várias histórias" e considerando a aprendizagem no âmbito doméstico, por exemplo, Oliveira (2005, p. 60) observa que:

Se o âmbito doméstico favoreceria, em alguns casos, a ascensão de escravos à leitura e à escrita, disso resultam, é óbvio, diversos graus de contato entre esses escravos e as habilidades de ler e escrever. Essa história, sendo assim, apresenta-se multifacetada, constituída de inúmeras nuances. Se algum dia surgirem trabalhos que trilhem esse caminho, o que emergirá não será uma história, mas várias, tantas quantas forem os casos revelados. (OLIVEIRA, 2005, p. 60).

Assim, se reconhece a dificuldade do proposto e igualmente que do estudo em andamento derivará não uma história, mas variadas e singulares histórias dos "sem arquivos escritos": negros e negras escravizadas no Brasil, no caso do presente trabalho.

\section{Aprendizagem da leitura e escrita entre a população escravizada}

Historiadores e historiadoras da educação têm procurado aliar-se ao movimento de ampliação das perspectivas historiográficas de análise da escravidão e da sua abolição no Brasil. Para Fonseca (2002, p. 15), "trata-se de um confronto com as teorias que coisificaram os escravos e que os qualificaram como seres incapazes de pensar o mundo a partir de suas

\footnotetext{
${ }^{2}$ Disponível em http://memoria.bn.br/hdb/periodo.aspx.

${ }^{3}$ Segundo Amantino (2006), Gilberto Freyre foi pioneiro, desde os anos de 1930, no uso de anúncios de jornais nos estudos da historiografia da escravidão. A culminância desses estudos foi a publicação da obra $O$ escravo nos anúncios de jornais brasileiros do século XIX, em 1963. Assim, de acordo com Amantino (2006, p. 60), mesmo tendo recebido algumas críticas, os pesquisadores seguiram as orientações de Freyre e "algumas pesquisas e artigos foram produzidos sobre o cotidiano da escravidão e fugas de escravos utilizando como fontes principais os jornais publicados em variadas regiões e períodos do século XIX". Outro clássico nessa área é o livro de Lilia M. Schwarcz, Retrato em branco e negro: jornais, escravos e cidadãos em São Paulo no final do século XIX, de 1987.
} 
próprias experiências e independente dos sentidos impostos pelos senhores de escravos". Configura-se, pois, como uma historiografia que pretende "recuperar um mundo criado pelos escravos dentro da sociedade escravista e [...] ampliar a margem de compreensão acerca das formas de ação dos negros escravizados, conferindo o significado de resistência a atitudes que até então não eram vistas dessa forma" (FONSECA, 2002, p. 15).

Nesse sentido, reconhecer processos de ensino e aprendizagem das habilidades do ler e do escrever, além de práticas de leitura e escrita entre escravos e escravas é fundamental, embora reconhecidamente difícil do ponto de vista da pesquisa, pois trata-se do esforço de escrever parte da história dos "sem arquivos":

A educação escolar do escravo é totalmente proibida no Brasil e os próprios forros não têm o direito de frequentar aulas. Esta proibição será mantida durante toda a época da escravidão, mesmo durante a segunda metade do século XIX, em plena desagregação do sistema servil. Senhores e curas que resolvem ensinar a leitura e a escrita a escravos agridem as regras estabelecidas e são poucos. Eis porque o escravo brasileiro é um desconhecido, sem arquivos escritos. (MATTOSO, 2001, p. 113 apud OLIVEIRA, 2005, p. 51. Grifo meu).

Mesmo assim, "[...] se pode cogitar da hipótese de que os negros não se mantinham passivos em relação a saber ler e escrever; para eles, esse aspecto parece ter alguma representação positiva e, conscientes disso, advinha o incentivo a ele" (OLIVEIRA, 2005, p. 62). Essa assertiva de que escravos e negros livres e libertos não eram passivos diante das possibilidades de aprendizagem é central quando se trata da pesquisa da temática em pauta. Perseguir qualquer pista, por mais indireta que seja, para identificar as ações e práticas da população escravizada no que tange às estratégias para aprender e ensinar a leitura e a escrita é fundamental, incluindo a hipótese de que inclusive internamente ao grupo, ou seja, entre eles, pudesse haver maneiras de transmissão desses saberes. Em se tratando de estratégias familiares, o autor supracitado retrata que:

[...] em 1835, quando foram interrogados negros suspeitos de terem participado do levante dos Malês, Ignácio Santana, nagô liberto de idade já bem adiantada, declarou que "se ocupa com mandar ensinar a seus filhos hum a carpina, outro na escola e a crear o outro que ainda hé muito pequeno". Embora não esteja claro o que significa exatamente o termo escola, certo é que não se trata da aprendizagem de uma profissão específica, porque, se assim o fosse, tê-lo-ia declarado Ignácio Santana, como fez para o seu primeiro filho citado. (OLIVEIRA, 2005, p. 62-63).

Ainda na esteira de identificar o domínio da leitura e da escrita entre a população escravizada o argumento de Luz (2013, p. 76), baseado no estudo de Karasch (2000), parece bastante pertinente. Ele afirma que alguns africanos que chegavam ao Rio de Janeiro

[...] já haviam aprendido a falar, ler e escrever em português na África. Outros eram crioulos que aprenderam a língua em alguma das colônias portuguesas, mas havia também escravos que vinham de regiões da África onde o vocabulário português ou a própria língua tinham sido assimilados, graças ao longo contato com os portugueses ou com mercadores que usavam o português. Assim, é perfeitamente possível 
que alguns dos escravos alfabetizados do Rio tivessem aprendido a ler e escrever português na África, ou com outros escravos da cidade que continuavam a transmitir a língua de 'pai para filho'.

É preciso reconhecer, contudo, quão difícil é identificar essas histórias e igualmente a controvérsia quando se trata dos números e índices sobre o domínio da leitura e da escrita, ou de um ou de outro, entre a população escravizada. Considerando o primeiro censo oficial feito no Brasil, em 1872, os dados no que tange à instrução dos escravos nesse período são os reproduzidos no Quadro 1. Ressalta-se que o censo registrou a situação dessa população apenas nos seguintes aspectos: Sabem ler e Analphabetos. Mesmo considerando os limites do Censo, especialmente porque se trata do século XIX, quando a prática censitária estava se instituindo no Brasil e referente à uma população que não era socialmente reconhecida, os dados são os seguintes:

Quadro 1: População escrava que sabia ler e analfabeta pelo Censo de 1872

\begin{tabular}{|l|c|c|c|c|c|}
\hline & $\begin{array}{c}\text { Números de } \\
\text { pessoas }\end{array}$ & Sabem ler & \% & Analfabetos/as & $\%$ \\
\hline Total & 1.510 .806 & 1.403 & $0,09 \%$ & 1.509 .403 & $99,91 \%$ \\
\hline Homens & 805.170 & 958 & $0,12 \%$ & 804.212 & $99,88 \%$ \\
\hline Mulheres & 705.636 & 445 & $0.06 \%$ & 705.191 & $99,94 \%$ \\
\hline
\end{tabular}

Fonte: RECENSEAMENTO DO BRAZIL EM 1872.

Se o índice de analfabetismo entre a população de um modo geral era alto no período, no caso dos escravos e escravas, como se pode ver pelos dados do Quadro 1, era ainda maior. Segundo Ferraro \& Kreidlow (2004), considerando o Censo de 1872, a taxa geral de analfabetismo do país era de $82,3 \%$ para as pessoas de 5 anos ou mais, situação que se manteve inalterada pelo menos até o segundo Censo, realizado em 1890 (82,6\%), já no início da República, como demostram os autores citados. Para a população escravizada, conforme apresentado no Quadro 1, o índice de analfabetos era de 99,91\%, portanto aqueles que sabiam ler representaria um percentual de apenas $0.09 \%$. Tomando separadamente homens e mulheres os índices não são muito mais expressivos, como se vê. Assim, essa é mais uma razão que justifica o presente estudo e move a curiosidade científica para procurar entender quem eram esses indivíduos, como e quem os alfabetizava. Diante dos ínfimos números do Censo de 1872 daqueles que foram registrados como os que sabiam ler, pergunta-se: como esses sujeitos aprenderam tais habilidades (ler, ou, quiçá, ler e escrever em alguns casos) em um contexto tão adverso, de exclusão social e de não reconhecimento da sua condição humana? Essa pergunta é extremamente inquietante, de difíceis e possivelmente de múltiplas respostas. Persegui-la não tem sido uma tarefa simples.

Para Oliveira (2005, p. 69), há indícios que explicam "o porquê de o analfabetismo não se ter feito presente em $100 \%$ da população escrava". O supracitado autor destaca três aspectos que podem ajudar a explicar esse fenômeno: a) Relações afetuosas dos escravos com a família senhorial; b) Especialização de algumas profissões, que exigiam algum conhecimento da leitura e escrita; c) $\mathrm{O}$ valor positivo da alfabetização entre negros e o papel das irmandades negras. (OLIVEIRA, 2005, p. 69).

Considera-se todas as hipóteses que explicam a alfabetização entre a população escravizada - independente da sua quantificação - como plausíveis e importantes. Muitas delas podem ser apenas pistas indiciárias, mas que devem e podem ser consideradas e perseguidas, especialmente nesse esforço necessário da escrita "das histórias dos sem arquivos". Em razão disso, na sequência, 
destacam-se alguns dados coletados na pesquisa realizada e que, algumas vezes, de forma indireta, permitem problematizar o proposto: a aprendizagem da leitura e da escrita entre a população escravizada: onde, como e com quem aprendiam a ler escravos e escravas no Brasil?

\section{Os indícios do domínio do ler e do escrever entre a população escravizada: anúncios de fugas e de vendas/compras de escravos}

Em algumas situações os "sem arquivos", quando aparecem em registros históricos, são homens e mulheres sem nomes e identidades. Para os casos dos escravizados, isso era recorrente. Em geral quando aparecem em registros, como os anúncios de jornais, por exemplo, são reduzidos a uma ou mais características dadas pelo pertencimento étnico-racial: um negro, um mulato, um crioulo, um preto, um escravo cabra, com feições de índia, em estado de prenhez, peitos largos, boca grande, dentes brancos, com cicatrizes, entre outros, como revelam os dados dos jornais coletados na pesquisa ${ }^{4}$. Em outros casos, são pessoas com apenas o primeiro nome, além das características físicas e das habilidades: Dyonisio, Silverio, Francisca, por exemplo. Nas Figuras 1, 2, 3 e 4, a seguir, são apresentados exemplos de avisos e anúncios de venda de escravos ou casos em que eles eram procurados por fuga:

Figura 1: Aviso

\section{AVISOS,}

Vende-se hum crioulo de idade de 20 annos; sabe ler, escrever a entend de de Alımbiqueiro; quem o quizer comprar, dirija-se a cast de Paslo Joaquim Texeira Gonsalves so Beco do Garapa.

Fonte: Idade D’Ouro do Brazil, 1813, p. 02.

Figura 2: Aviso

\section{A VISOS.}

Joaguim Malaquias da Silva na rua diraita da Fonte dos Padres N. 44, tom para vender hum negro que sabe berm ler eserever, e contar.

Fonte: Idade D’Ouro do Brazil, 1818, p 02.

Figura 3: Anúncio

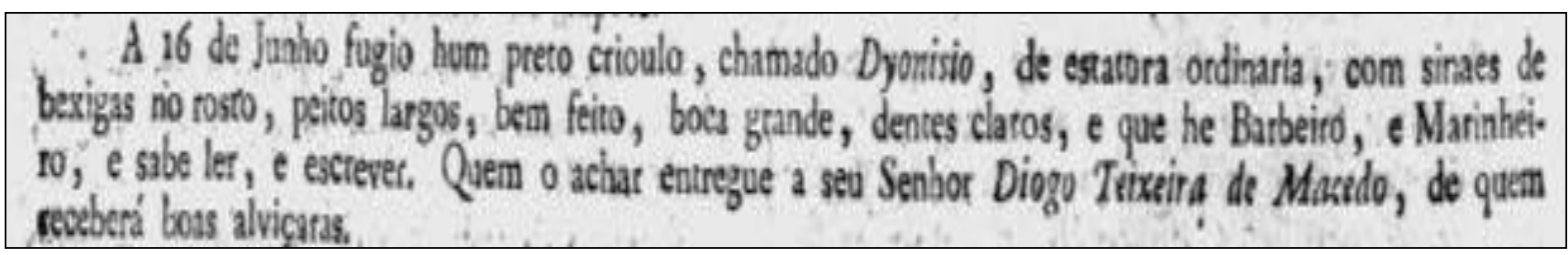

Fonte: Gazeta do Rio de Janeiro, Rio de Janeiro, 1812, p. 02.

\footnotetext{
${ }^{4}$ [...] "como estes anúncios eram usados como mecanismos para identificar escravos fugidos, era necessário que o senhor de cada um, fornecesse informações que tornassem possível a sua captura” (AMANTINO, 2006, p. 72).
} 
Figura 4: Anúncio

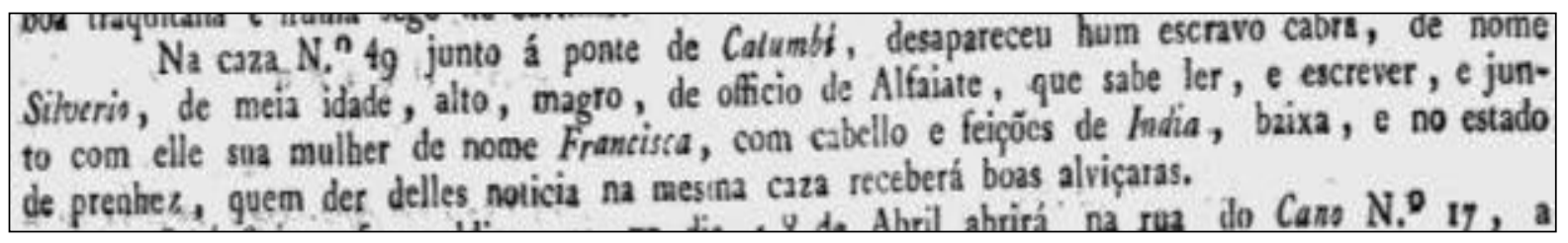

Fonte: Gazeta do Rio de Janeiro, 1820, p. 02.

Como se pode ver, todos os anúncios reproduzidos anteriormente têm em comum a informação de que o escravo sabia ler e escrever ou, como em um dos casos, ler, escrever e contar. Além disso, percebe-se que alguns tinham profissões especializadas: alambiqueiro, barbeiro, marinheiro, alfaiate. Oliveira (2005, p. 61), considerando outro estudo, sobre o Município da Corte, em relação à especialização de algumas profissões exercidas por escravos, indica que

[...] desde a chegada da Família Real, com o crescimento urbano e as novas oportunidades de negócio, os pequenos proprietários tiveram interesse em especializar seus escravos em determinadas tarefas, porque, através delas, podiam aumentar as rendas em função do seu trabalho.

Para o que aqui mais interessa o autor afirma que havia

[...] escolas especializadas no treinamento de escravos, que lhes ofereciam, além das habilidades específicas ao ofício, a iniciação na leitura, na escrita e na contagem Desse modo, [...] a aquisição de determinadas especializações dependia da vontade ou da possibilidade dos senhores de treiná-los e, entre os escravos, os especializados compunham uma minoria, o que significa dizer que, se há uma relação entre alfabetização e ofícios especializados na Corte, devem ter sido poucos os escravos que aprenderam a ler, escrever e contar em função da aprendizagem desse ofício. (OLIVEIRA, 2005, p. 61).

Não se pode imaginar, portanto, que a relação entre serviços especializados e o número de escravos alfabetizados fosse assim tão expressiva. Além disso, é ainda Oliveira (2006, p. 61) quem relembra que os escravos, em sua maioria, estavam "ocupados em tarefas que não careciam de especialização alguma". Quem, quando, onde e como escravos eram alfabetizados - em uma ou outra situação, ou seja, desempenhando ou não funções especializadas - é um desafio de pesquisa que se tem tentado vencer.

Para o caso dos anúncios, localizou-se, ainda, alguns casos em que se procuravam escravos que soubessem ler e escrever, indicando, além do domínio dessas habilidades entre essa população, para situações em que saber ler e escrever poderia contribuir para posições e condições de trabalho menos severas e adversas, como as da lavoura, das charqueadas ou dos engenhos, por exemplo. Na Figura 5, reproduz-se um anúncio em que é revelado o interesse na compra de um escravo que soubesse bem ler e escrever. $\mathrm{O}$ fato de o anúncio referir que o interessado em vender deveria se dirigir ao Tabelião Mata pode indicar algum serviço especializado no próprio Tabelionato. Contudo, considerações como essa são apenas probabilidades, mas que são importantes na problematização das questões propostas: 
Figura 5: Anúncio

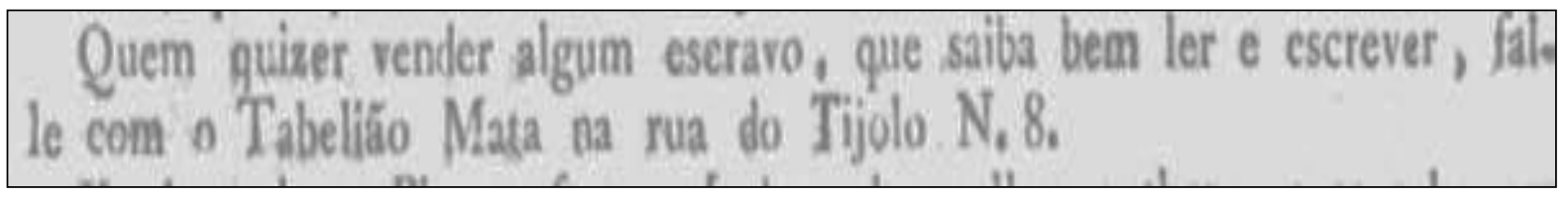

Fonte: Idade D’Ouro do Brazil, 1814, p. 02.

Como se pode ver nessa seção, há dados que revelam o domínio do ler e do escrever entre pessoas escravizadas, embora eles sejam rarefeitos, parciais e insuficientes para conclusões mais gerais. Mas, para além dessa constatação, propôs-se outras questões na pesquisa. A seguir, o esforço em tentar responder, pelo menos, uma delas.

\section{Quem ensinava as primeiras letras à população escravizada?}

Primeiro, destaca-se que a procura e a oferta de pessoas - homens e mulheres -, para ensinar a ler e a escrever era relativamente comum no início do século XIX, indicando para a importância que o ensino doméstico tinha nesse contexto. Ele poderia ocorrer tanto na casa dos aprendizes, quanto das pessoas que ofereciam os serviços que, como se verá, poderia incluir o ensino da leitura e da escrita junto com o de outras habilidades. Os anúncios a seguir, reproduzidos nas Figuras 6 e 7, são apenas alguns exemplos disso:

Figura 6: Anúncio

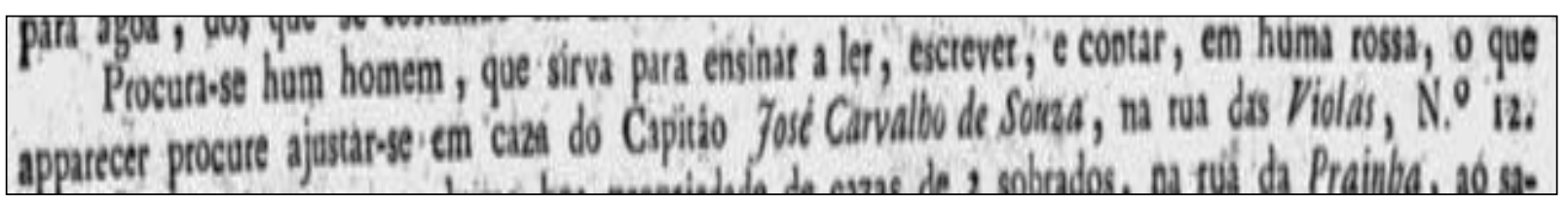

Fonte: Gazeta do Rio de Janeiro, 1815, p. 02.

Figura 7: Anúncio

X. Ama Maria Roza faz saber ao publico, que se propŏe a ensinar meninas, e mesmo aec grinhas ao trabalho de costura e borlas, e querendo até ler e excrever, póden procurat as rua do Alecrion N.G III, que se ajusturí por preço commodo. $x$

Fonte: Gazeta do Rio de Janeiro, 1821, p. 02.

No caso reproduzido na Figura 7, como se pode ler, trata-se de uma mulher que publicou um anúncio propondo-se a ensinar às meninas as prendas domésticas, costurar e bordar, e querendo, até ler e escrever, incluindo negrinhas. Supor que, por vezes, mesmo meninas escravas pudessem ser levadas aos domicílios para as aprendizagens referidas não parece tão improvável assim. Nesse sentido, a pergunta acerca de quem ensinava aos escravizados a ler e a escrever poderá ter múltiplas e diferentes respostas, na perspectiva das várias histórias.

Padres também se colocam à disposição para aulas de ler, escrever e contar. $\mathrm{O}$ anúncio a seguir, da Figura 8, embora não se refira em momento algum à população a que se destinam as aulas (embora o fato de haver cobrança já possa indicar), no cruzamento com outras fontes e dados, tal anúncio faz sentido e contribui para reafirmar a "condição de professores" dos padres que viviam no Brasil: 
Figura 8: Anúncio

O Padre Agostinbo Fesé da silva, querendo ser util 20 Público, com licença de S. A. R. 0 Pribcipa Regente Nosso Senhor, tem aberto dula de ler, escrever, e contar, rudimentos da Religiáo, Monal, Politica, \&c. Os Scahores que quizerern aproveitar-se do seu prestimo no ensino de seus fthos, pala gratificrçio mensal de $1 \$ 280$ reis, dirija-se i rua do Sabio a caza N. ${ }^{0} 31$.

Fonte: Gazeta do Rio de Janeiro, 1814, p. 02.

Há indícios de que alguns padres ensinavam também escravos e escravas a ler e a escrever, mas não há como saber se era o caso de Agostinho José da Silva.

Um dos casos conhecidos de uma escrava alfabetizada que supostamente teria aprendido a ler e a escrever com os padres jesuítas é o de Esperança Garcia. Pouco se sabe sobre a negra escravizada Esperança Garcia, onde, nem quando nasceu, por exemplo. Contudo, sabe-se que viveu no século XVIII, na região que hoje é o estado do Piauí, quando Maranhão e Piauí ficavam na mesma capitania (SOUZA, 2015; ROSA, 2012). Ela se destacou por ter escrito uma carta $^{5}$ ao governador do Piauí, Gonçalo Lourenço Botelho de Castro, reivindicando o direito de ficar junto ao marido e aos filhos e denunciando o sistema escravagista. Segundo Souza (2015, p. 3), "a 'Carta' de Esperança Garcia faz uma fotografia real da experiência humana de homens e mulheres negras que desceram aos infernos da escravidão". Além disso, para o autor, a carta representa a resistência dos escravos e "faz desmoronar os estereótipos raciais acerca da submissão 'natural' do escravo negro" (SOUZA, 2015, p. 4).

Outro padre, Candido Pereira de Lemos, em anúncio publicado em um jornal em 1833, alerta aos mestres de embarcações e canoeiros que não admitissem em suas embarcações, sem suas ordens expressas, o escravo Liborio. O fato de Liborio saber ler e escrever facilitaria uma possível fuga, uma vez que ele poderia se fazer passar por liberto:

Figura 9: Anúncio

- O Padre Candido Pereira de Lemos faz
saber aos Snrs., que pussuem Canôas, ou ou-
tra qualquer sorte de embarcaçōes, e aos
Mestres, das mesmas, para que nāo admittãe
n'ellas sem ordem sua bem especificada hum
escravo por nome Liborio, mulato laranjo, de
idade de. 30 annos pouco mais, ou menos,
baixo, grosso, de entrada alta, e beiços gros--
sos, e tem hum signal foveiro da sobrancelha,
e lado direito athe, á bocca, o qual he do ser-
tão, e pertendeo hum dia d'estes, e talvez
ainda se resolva a fugir, e he facil passar por
liberto, porque sabe lêr, e escrever.

Fonte: O Publicador Oficial, 1833, p. 02.

$\mathrm{O}$ que se quer reafirmar com tal anúncio é justamente que padres, como a historiografia já demostrou, eram proprietários de escravos. Lançar a suposição de que eles os ensinavam a ler, a escrever e/ou contar, não é infundada, ou mesmo que os escravos e escravas aprendiam por observação e atenção ao ensino ministrado à outras crianças e jovens, brancas e ricas, igualmente deve ser uma hipótese considerada nesse contexto.

\footnotetext{
${ }^{5}$ A carta é datada de 6 de setembro de 1770 e uma cópia foi descoberta pelo historiador Luiz Mott, em 1979, no Arquivo Público do Piauí. Segundo consta, a original está em Portugal, nos registros sobre a história colonial brasileira (SOUZA, 2015; ROSA, 2012).
} 
Há, contudo, nos anúncios, evidências explícitas do ensino da leitura e da escrita às crianças escravas, como no caso a seguir:

Figura 10: Anúncio

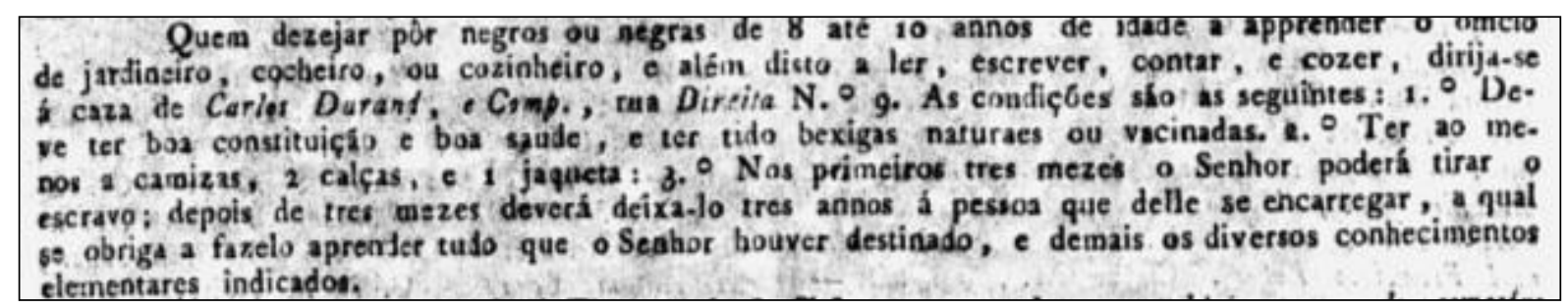

Fonte: Gazeta do Rio de Janeiro, 1819, p. 02.

O conteúdo desse anúncio de 1819 é deveras significativo na pesquisa realizada e considerando as questões propostas. Além de referir à questão de gênero, negros e negras, e a suposta condição de escravo dos aprendizes, revela outro dado importante: o ensino da leitura e da escrita, tanto para meninas quanto para meninos escravos, estava associado ao ensino de algum ofício especializado. Nesse caso, jardineiro, cocheiro, cozinheiro, costureira. O espaço e os responsáveis pelo ensino na casa de Carlos Durand e Comp., impunham algumas exigências aos senhores que quisessem deixar aprendizes sob sua responsabilidade: as condições de saúde, as vestimentas e o tempo de permanência e de aprendizagem, ou seja, como se lê, em três meses poderia o senhor tirar o escravo, caso contrário, depois disso, deveria mantê-lo por pelo menos três anos sob a reponsabilidade do encarregado. Três anos era um tempo relativamente longo para aprendizagem. Além da qualificação no ofício requerido, as habilidades de leitura e de escrita poderiam ser desenvolvidas adequadamente nesse tempo.

Sobre a aprendizagem de um ofício pelos escravos, é preciso destacar ainda que o trabalho deles "proporcionava um lucro certo e fácil para o senhor. Por isso, ensinavam-lhes um ou mais ofícios e os exploravam o quanto podiam, vivendo à custa de seu trabalho" (LUZ, 2013, p. 75), seja colocando-os como escravos de ganho ou alugando-os a terceiros. Contudo, é necessário relembrar que o domínio de conhecimentos profissionais especializados e o trabalho fora das vistas do senhor também permitia, aos escravos, “circular com mais 'liberdade' pelas ruas da cidade, no sentido de escolher e estabelecer novos laços de amizade, família ou patronagem, aproximando-se quase da indiferenciação do mundo dos livres" (LUZ, 2013, p. 75). Quiçá nesses momentos de circulação mais livre e de estabelecimento de outras relações não estivesse também a possibilidade de os escravos aprenderem a ler e a escrever, ou de, ao aprenderem um ofício, serem simultaneamente instruídos na leitura e na escrita. Embora Luz (2013, p. 76) afirme que não há provas de que as "escolas" privadas de caráter vocacional ou de aprendizado de uma profissão que recebiam escravos também ensinassem a ler e escrever, os anúncios aqui apresentados indicam essa possibilidade, uma vez que a oferta de pessoas disponíveis a ensinar ambos, saberes profissionais e primeiras letras, é recorrente nos jornais pesquisados. Obviamente que os exemplos aqui referem-se mais diretamente à aulas privadas, mas considerando que essa era a realidade da educação no Brasil no final do século XVIII e primeiras décadas do século XIX tem sentido considera-las espaços de instrução por excelência e há evidências desse ensino simultâneo, dos ofícios e das letras, nessas aulas privadas.

Então, na sequência, apresenta-se mais um exemplo dessa relação entre o ensino das primeiras letras e o ensino de tarefas da casa e de ofícios especializados: 
Figura 11: Anúncio

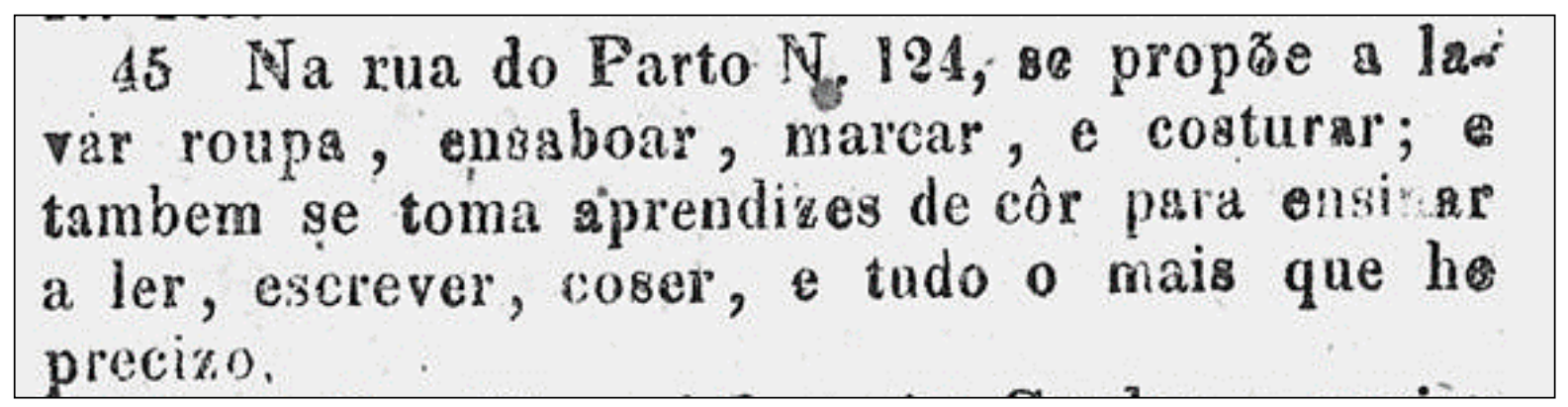

Fonte: Diário do Rio de Janeiro, 1826, p. 02.

Em 1826, na rua do Parto, no Rio de Janeiro, há probabilidade que houvesse, entre os aprendizes de cor, algum que fosse escravo. Além disso, não é demais dizer que ensinar a lavar roupa, ensaboar, marcar, costurar, eram tarefas domésticas ensinadas por mulheres, para mulheres. Nesse contexto, pode-se inferir que mulheres ensinavam meninas escravas a ler e a escrever. No que tange as questões de gênero, especificamente de meninas escravas, outros dados foram localizados na pesquisa e merecem atenção. É o proposto a seguir.

\section{Mulheres ensinavam meninas negrinhas escravizadas a ler?}

Como destacou-se com o caso de Anna Maria Roza, no anúncio anteriormente reproduzido, na Figura 7 , senhoras ${ }^{6}$ se propunham a ensinar tarefas domésticas ou ofícios às meninas. No anúncio a seguir, da Figura 12, a qualificação é dada pelo gênero e pelo estado civil, dois marcadores sociais importantes na sociedade do século XIX: trata-se de uma senhora casada que se disponibilizava a ensinar meninas, igualmente negrinhas:

Figura 12: Anúncio

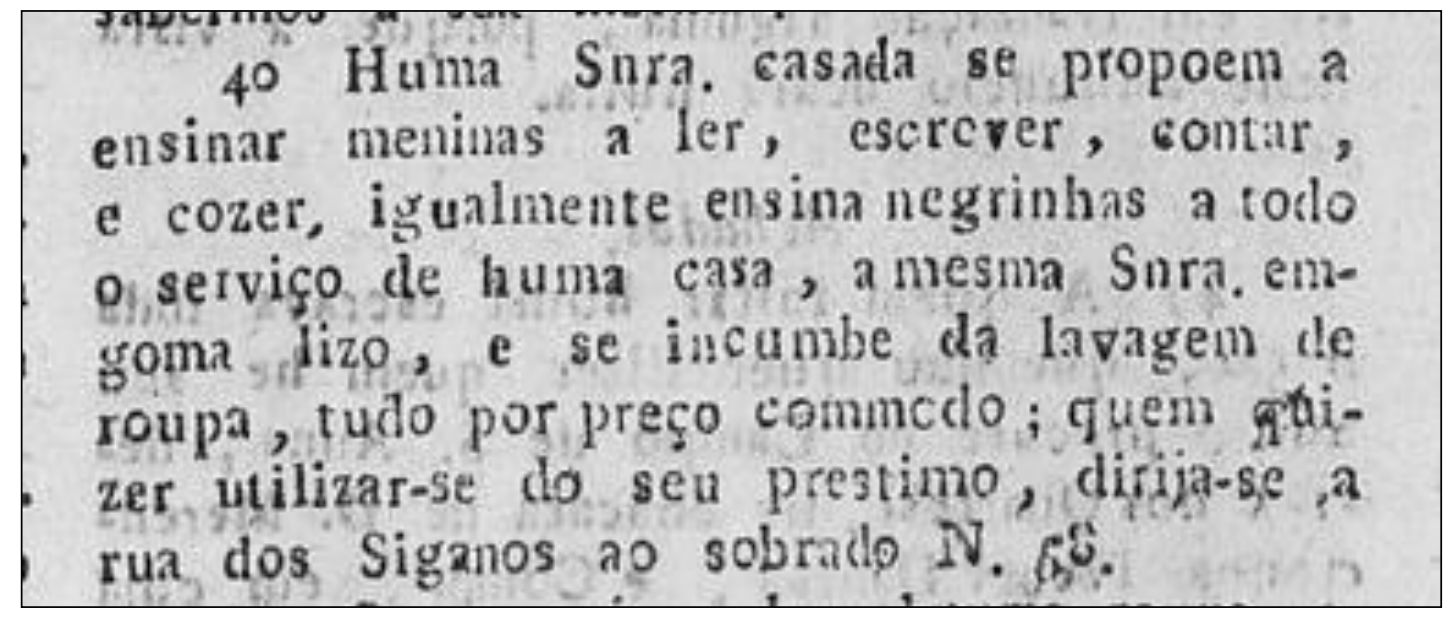

Fonte: Diário do Rio de Janeiro, 1822, p. 02.

\footnotetext{
${ }^{6}$ Talvez não fossem exatamente professoras as senhoras que ensinavam a ler e a escrever. É preciso destacar que todos os anúncios coletados na pesquisa são anteriores, por exemplo, à criação da primeira Escola Normal no Brasil, que foi em Niterói, em 1835. Além disso, trata-se de um período em que as condições de escolarização pública ainda eram diminutas. As escolas, via de regra, eram fundamentalmente aulas públicas e particulares ministradas na casa mestre ou em outro espaço doméstico, muitas vezes alugado e mantido por um professor (LUZ, 2013). As escolas e aulas do período imperial, especialmente no início, eram ainda, como afirmou Faria Filho (1999), uma herança do período colonial, das escolas régias ou das cadeiras públicas de primeiras letras. Sobre a Escola Normal e a história da formação de professores no Brasil, ver Villela (2000). Sobre educação doméstica e o ensino no Brasil Oitocentista, ver especialmente Vasconcelos (2005).
} 
Se a senhora casada, da Rua dos Siganos, do sobrado 58, no Rio de Janeiro, em 1822, que ensinava meninas a ler, escrever, contar e cozer, e às negrinhas todo serviço da casa, além de lavar roupas, ensinava também escravas, não é uma afirmativa que se possa fazer pelo anúncio publicado. Pode-se, contudo, especialmente considerando os anúncios que serão reproduzidos na sequência, considerar que essa possibilidade não é desproposital.

Em anúncio de 1816, Frederica, Carlota e Candida, ao que tudo indica três irmãs recém-chegadas da Europa, publicaram o que segue:

Figura 13: Anúncio

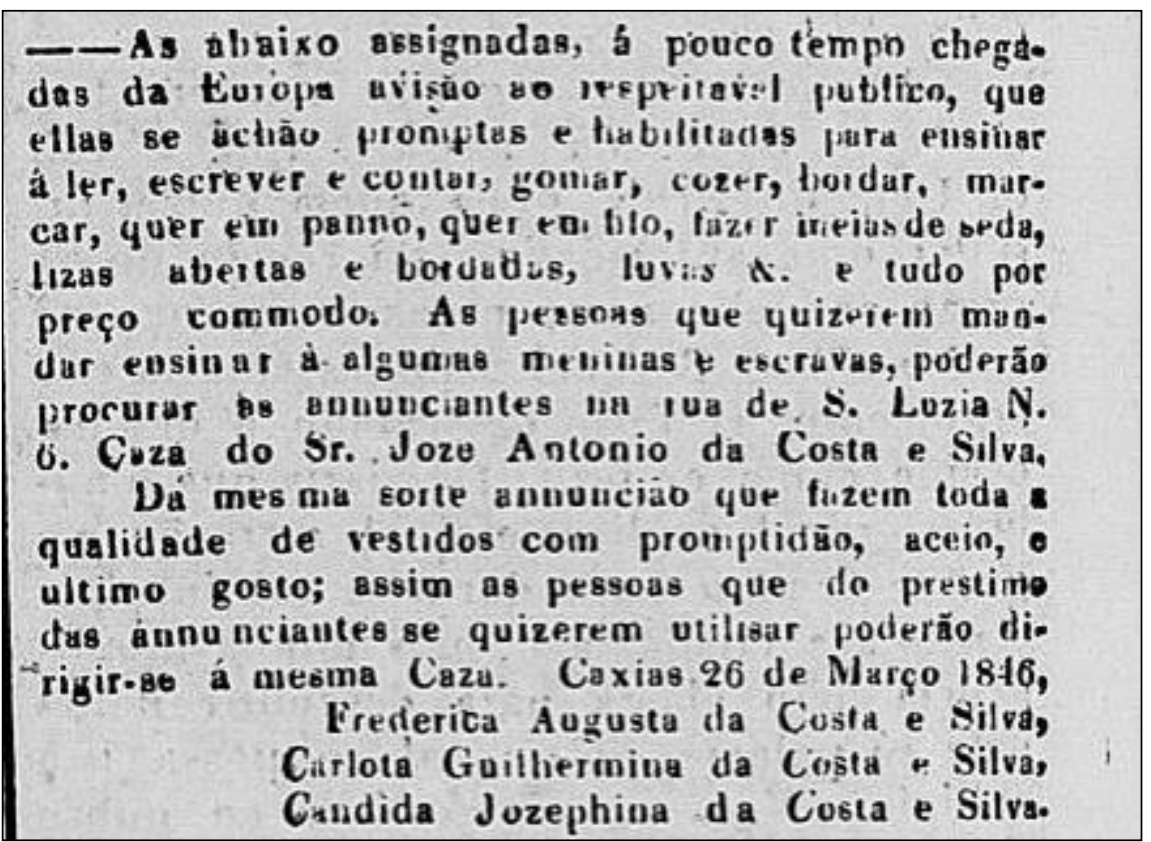

Fonte: Jornal Caxiense, 1816, p. 03.

Frederica, Carlota e Cândida, todas Costa e Silva, provavelmente filhas de Joze Antonio da Costa e Silva, ensinavam a ler, escrever, contar, engomar, costurar, bordar, fazer meias e luvas às meninas, incluindo as escravas, na própria residência, nesse caso, portanto, em um contexto exclusivamente feminino: uma tarefa de mulheres às aprendizes meninas, tanto livres, quanto escravas. Essa era uma realidade, portanto, no Brasil no início do século XIX. Assim também fazia D. Delfina Prates, em 1821, igualmente no Rio de Janeiro: ensinar meninos e meninas e também escravas:

Figura 14: Anúncio

21 Qualquer Sr. ou Sra., que tiver meninos ou meninas para mandar educar, aprender a ler, escrever, e tambem escravas, e as queiras mándar aprenter a cozer, engomar, e bordar de branco e de ouro, procure a D. Delfina l'rates' na rua da Misericordia. no N. ${ }^{\bullet},{ }_{L},{ }^{\circ}$ andar. .

Fonte: Diário do Rio de Janeiro, 1821, p. 02.

Explicitamente, como se pode ler, Delfina Prates aceitava ensinar às escravas prendas domésticas de costurar, engomar e bordar, além de leitura e escrita aos meninos e meninas. 
Tem sentido considerar que nessas aulas, as habilidades do lar e da leitura e da escrita fossem ensinadas a ambas, tanto às meninas livres, quanto às escravas.

De modo geral, autores que se ocupam da educação, escolarização e/ou alfabetização da população escrava reconhecem a dificuldade de saber como e onde eles aprendiam as primeiras letras. Isso é ainda mais complicado quanto se trata das mulheres escravizadas. Luz (2013, p. 77) afirma que "é difícil saber exatamente como aprendiam a ler e escrever, especialmente as mulheres, numa sociedade em larga medida analfabeta". Os anúncios coletados na pesquisa e apresentados no presente artigo oferecem dados importantes para que se possa desenhar mais nitidamente o mapa da aprendizagem da leitura e da escrita entre negros e negras escravizados no Brasil. Trata-se, ainda, de um mapa bastante parcial e limitado que, paulatinamente, pode e deve ser completado, senão na sua totalidade - já que se trata dos "sem arquivos escritos" e é uma ilusão, obviamente, pensar em uma "história total", mas compondo as "várias e múltiplas histórias".

Por fim, é preciso salientar ainda que, como para outros espaços, tempos e grupos sociais, o domínio do ler e do escrever entre a população escravizada supunha diferentes níveis e capacidades: no que tange à leitura, havia, provavelmente, desde aqueles que liam apenas letras soltas ou sílabas, algumas poucas palavras ou frases esparsas, até os fluentes na leitura capazes de ler jornais, livros, panfletos etc; do ponto da escrita, possivelmente havia desde aqueles que apenas assinavam o próprio nome até os que eram capazes de escrever bilhetes, cartas, ensaios, redigir notícias, petições, etc. Essas diferenças também configuram as várias histórias dessa população e de sua relação com a cultura escrita. Histórias que urge contar! E é preciso relembrar que à história cabe enfrentar o grande óbice de ultrapassar os silêncios (FIGUEIREDO, 2015).

\section{Considerações finais}

Como se viu através dos anúncios dos jornais, padres, senhoras - possivelmente benfeitoras, moças vindas da Europa, como era o caso das irmãs Costa e Silva, por exemplo -, estavam entre as pessoas que ensinavam escravos e escravas a ler e a escrever, cujas aulas poderiam acontecer nas próprias residências daqueles que se ofereciam para ensinar ou nas casas dos aprendizes.

Segundo Fonseca (2002), como foi anteriormente citado, em 1835 foi legalmente determinado que os escravos não poderiam frequentar escolas. Veja-se que os dados apresentados nesse estudo foram todos anteriores a essa data, referem-se às três primeiras décadas do século XIX. Poderia, assim, lançar-se os seguintes questionamentos: essa lei teria freado um processo em andamento, de ensinar e escolarizar negros e negras escravas? Anterior a essa data, havia mais pessoas que se dispunham a ensinar a população escravizada? Esse ensino, das primeiras décadas do século XIX (e possivelmente anterior a isso), teria permitido que um pequeno número de escravizados fosse alfabetizado e pudesse transmitir esses saberes? Não é infundado pensar que os próprios escravos, homens, mulheres e crianças, reproduzissem entre si os conhecimentos da leitura e da escrita. Possivelmente redes de ensino entre os próprios escravizados funcionassem nos espaços em que viviam e nos poucos tempos que dispunham. Por ora, trata-se, novamente, de assertivas e perguntas mobilizadoras de reflexão, de hipóteses e de possibilidades de pesquisa.

Um dos resultados importantes do estudo revela a relação entre o ensino das primeiras letras e o ensino de tarefas domésticas e ofícios especializados. Considera-se que essa é uma pista de pesquisa importante: os anúncios manifestam que as mesmas pessoas que se dispunham a ensinar atividades e ofícios especializados, também ensinavam a leitura e a escrita, para crianças livres e escravas. Certamente que a separação do ensino dessas habilidades, que acontecia fundamentalmente nas residências, era algo difícil de estabelecer. Assim, aposta-se na ideia da simultaneidade de ambas. 
Por fim, é preciso pensar nas contradições do sistema escravagista também no que tange à instrução dos escravos. Se, por um lado, ter um escravo ou escrava que soubesse ler e escrever trazia possíveis benefícios ao senhor, uma vez que agregava valor nas relações de trabalho e de compra e venda, por outro, poderia representar um risco à ordem, ao controle e à hierarquia estabelecida. Possivelmente escravas e escravos alfabetizados representassem, aos senhores e ao sistema escravagista, um perigo real, uma vez que aprender a ler e a escrever sempre foi, na história das sociedades e dos sistemas altamente desiguais e injustos, uma forma de empoderamento dos excluídos. Entre os escravizados, o domínio da palavra escrita significou uma estratégia de resistência e de luta, mesmo que poucos tenham tido acesso a isso. Angela Davis (2016, p. 34), referindo especificamente às mulheres escravizadas, afirma que a resistência envolvia, em muitos casos, "ações mais sutis do que revoltas, fugas e sabotagens. Incluía, por exemplo, aprender a ler e a escrever de forma clandestina [ou não autorizada], bem como a transmissão desse conhecimento aos demais".

\section{Referências}

AMANTINO, Márcia. Os escravos fugitivos em Minas Gerais e os anúncios do Jornal "O Universal"- 1825 a 1832. Locus. Revista de História, Juiz de Fora, v.12, n.2, p. 59-74, 2006.

BARBOSA, Marialva. Escravos letrados: uma página (quase) esquecida. Revista da Associação Nacional dos Programas de Pós-Graduação em Comunicação, v.12, n.1, 2009, p.1-19. https://doi.org/10.30962/ec.v12i1.371

BASTOS, Maria Helena Camara. A educação dos escravos e libertos no Brasil: vestígios esparsos do domínio do ler, escrever e contar (Séculos XVI a XIX). Cadernos de História da Educação, v. 15, n. 2, 2016, p. 743-768. https://doi.org/10.14393/che-v15n2-2016-15

DAVIS, Angela. Mulheres, raça e classe. São Paulo, Boitempo Editorial, 2016.

FERRARO, Alceu R.; KREIDLOW, Daniel. Analfabetismo no Brasil: configuração e gênese das desigualdades regionais. Educação e Realidade, Porto Alegre, v. 29, n.2, p. 179-200, 2004.

FIGUEIREDO, Isabela. Cadernos de memórias coloniais. Lisboa, Editorial Caminho, S.A., 2015.

FONSECA, Marcus Vinicius. A educação dos negros: uma nova face do processo de abolição do trabalho escravo. Bragança Paulista: Editora da Universidade São Francisco, 2002.

FREYRE, Gilberto. O Escravo nos anúncios de jornais brasileiros do século XIX: tentativa de interpretação antropológica, através de anúncios de jornais, de característicos de personalidade e de deformações de corpo de negros ou mestiços, fugidos ou expostos à venda, como escravos, no Brasil do século passado. Recife: Imprensa Universitária, 1963.

LUZ, Itacir Marques. Alfabetização e escolarização de trabalhadores negros no Recife oitocentista: perfis e possibilidades. Revista Brasileira de História da Educação. v.13. n.1 [31]. 2013, p. 69-94. https://doi.org/10.4322/rbhe.2013.015 
MORAIS, Christianni Cardoso. Ler e escrever: habilidades de escravos e forros? Comarca do Rio das Mortes, Minas Gerais, 1731-1850. Revista Brasileira de Educação v. 12 n. 36 set./dez. 2007. pp. 493-504. https://doi.org/10.1590/S1413-24782007000300008

MOYSÉS. Sarita M. Affonso. Leitura e apropriação de textos por escravos e libertos no Brasil do século XIX. In: Revista de Ciência e Educação - Educação e Sociedade. São Paulo: Papirus, n.48, agosto/1994.

OLIVEIRA, Klebson. Negros e escrita no Brasil do século XIX: sócio-história, edição filológica de documentos e estudo linguístico. Universidade Federal da Bahia. Programa de Pós-Graduação em Letras e Linguística (Doutorado em Letras). Salvador, Bahia, 2005. 1198p; 2v. http://www.repositorio.ufba.br/ri/handle/ri/12042. Acesso em 15 jan. 2018.

ORO, Ari. Religiões Afro-Brasileiras do Rio Grande do Sul: Passado e Presente Estudos Afro-asiático. v.24, n.2, Rio de Janeiro, 2002. pp. 345-384. https://doi.org/10.1590/S0101$\underline{546 \times 2002000200006}$

RECENSEAMENTO DO BRAZIL EM 1872. Disponível em https://biblioteca.ibge.gov.br/visualizacao/livros/liv25477_v1_br.pdf. Acesso em 01 jul. 2019.

ROSA Sonia. Quando a escrava Esperança Garcia escreveu uma carta. Ilustração: Luciana Justiniani Hees. Rio de Janeiro: Pallas Editora, 2012.

SILVA, Alexandra Lima da. Flores de Ébano: a educação em trajetórias de escravizadas e libertas. Revista Brasileira de Pesquisa (Auto)Biográfica, Salvador, v.4, n.10, p.299-311 jan./abr. 2019. https://doi.org/10.31892/rbpab2525-426X.2019.v04.n10.p299-311

SOUZA, Elio Ferreira de. A "carta" da escrava Esperança Garcia do Piauí: uma narrativa precursora da literatura afro-brasileira. 2015. Disponível em http://www.abralic.org.br/anais/arquivos/2015_1455937376.pdf. Acesso em 15 jan. 2018.

SCHWARCZ, Lilia M. Retrato em branco e negro: jornais, escravos e cidadãos em São Paulo no final do século XIX. São Paulo: Cia das Letras, 1987.

VASCONCELOS, Maria Celi C. A casa e os seus mestres. Rio de Janeiro: Gryphus, 2005.

VILLELA, Heloísa de O. O Mestre Escola e a Professora. In: LOPES, Eliane et. al. 500 anos de Educação no Brasil. $2^{\mathrm{a}}$ ed. Autêntica. Belo Horizonte, 2000.

WISSENBACH, Maria Cristina C. Cartas, procurações, escapulários e patuás: os múltiplos significados da escrita entre escravos e forros na sociedade oitocentista. In: Revista Brasileira de História da Educação. São Paulo: Autores Associados, n.4, jul./dez., 2002. p.103-122. 


\section{Jornais}

A FEDERAÇÃO. Órgão do Partido Republicano. Sabbado, 24 de outubro de 1885, № 242, p. 02, Porto Alegre, 1885. Disponível em Biblioteca Nacional. Hemeroteca Digital Brasileira: http://memoria.bn.br/hdb/periodo.aspx. Acesso em 05 mar. 2018.

DIÁRIO DO RIO DE JANEIRO. Sexta feira, 2 de novembro de 1821, p. 02, Rio de Janeiro, 1821. Disponível em Biblioteca Nacional. Hemeroteca Digital Brasileira: http://memoria.bn.br/hdb/periodo.aspx. Acesso em 05 mar. 2018.

DIÁRIO DO RIO DE JANEIRO. Terça feira, 28 de maio de 1822, p. 02, Rio de Janeiro, 1822. Disponível em Biblioteca Nacional. Hemeroteca Digital Brasileira: http://memoria.bn.br/hdb/periodo.aspx. Acesso em 05 mar. 2018.

DIÁRIO DO RIO DE JANEIRO. Segunda Feira, 12 de junho de 1826, N. 09, p. 02, Rio de Janeiro, 1826. Disponível em Biblioteca Nacional. Hemeroteca Digital Brasileira: http://memoria.bn.br/hdb/periodo.aspx. Acesso em 23 jun. 2019.

GAZETA DO RIO DE JANEIRO. Impressão Regia. Quarta-feira, 15 de julho de 1812, № 57, p. 02, Rio de Janeiro, 1812. Disponível em Biblioteca Nacional. Hemeroteca Digital Brasileira: http://memoria.bn.br/hdb/periodo.aspx. Acesso em 22 mar. 2017.

GAZETA DO RIO DE JANEIRO. Impressão Regia. Quarta-feira, 8 de junho de 1814, № 46, p. 02. Rio de Janeiro, 1814. Disponível em Biblioteca Nacional. Hemeroteca Digital Brasileira: http://memoria.bn.br/hdb/periodo.aspx. Acesso em 03 jun. 2017.

GAZETA DO RIO DE JANEIRO. Impressão Regia. Sabbado, 22 de julho, 1815, No 58, p. 02. Rio de Janeiro, 1815. Disponível em Biblioteca Nacional. Hemeroteca Digital Brasileira: http://memoria.bn.br/hdb/periodo.aspx. Acesso em 03 jun 2017.

GAZETA DO RIO DE JANEIRO. Impressão Regia. Quarta-feira, 18 de setembro de 1819, $N^{o} 74$, p. 02, Rio de Janeiro, 1819. Disponível em Biblioteca Nacional. Hemeroteca Digital Brasileira: http://memoria.bn.br/hdb/periodo.aspx. Acesso em 22 mar. 2017.

GAZETA DO RIO DE JANEIRO. Impressão Regia. Sabbado, $1^{\circ}$ de abril de 1820 , s/n, p. 02, Rio de Janeiro, 1820. Disponível em Biblioteca Nacional. Hemeroteca Digital Brasileira: http://memoria.bn.br/hdb/periodo.aspx. Acesso em 22 mar. 2017.

GAZETA DO RIO DE JANEIRO. Impressão Regia. Sabbado, 07 de abril de 1821, No 28, p. 02, Rio de Janeiro, 1821. Disponível em Biblioteca Nacional. Hemeroteca Digital Brasileira: http://memoria.bn.br/hdb/periodo.aspx. Acesso em 22 mar. 2017. 
IDADE D'OURO DO BRAZIL. Bahia. Typographia de Manoel Antonio da Silva Serva. Terça feira, 3 de agosto de 1813, No 62, p. 02. Bahia, 1813. Disponível em Biblioteca Nacional. Hemeroteca Digital Brasileira: http://memoria.bn.br/hdb/periodo.aspx. Acesso em 03 jun 2017.

IDADE D'OURO DO BRAZIL. Bahia. Typographia de Manoel Antonio da Silva Serva. Sexta feira, 21 de outubro de 1814. N ${ }^{\circ}$ LXXXVV. Bahia, 1814. Acesso em 22 mar. 2017.

IDADE D'OURO DO BRAZIL. Bahia. Typographia de Manoel Antonio da Silva Serva. Terça feira, 14 de abril de 1818, $\mathrm{N}^{\circ}$ 30, p. 02. Bahia, 1818. Disponível em Biblioteca Nacional. Hemeroteca Digital Brasileira: http://memoria.bn.br/hdb/periodo.aspx. Acesso em 03 jun 2017.

IDADE D'OURO DO BRAZIL. Bahia. Typographia de Manoel Antonio da Silva Serva. Sexta feira, $1^{\circ}$ de janeiro de 1819, $N^{\circ}$ 01, p. 02. Bahia, 1819. Disponível em Biblioteca Nacional. Hemeroteca Digital Brasileira: http://memoria.bn.br/hdb/periodo.aspx. Acesso em 03 jun 2017.

JORNAL CAXIENSE, Segunda feira, 11 de mayo de1816, N. 10, p. 03, Rio de Janeiro, 1816.

O PUBLICADOR OFICIAL, Sabbado, 18 de maio de 1833, N. 160, p. 02, Rio de Janeiro, 1833. 